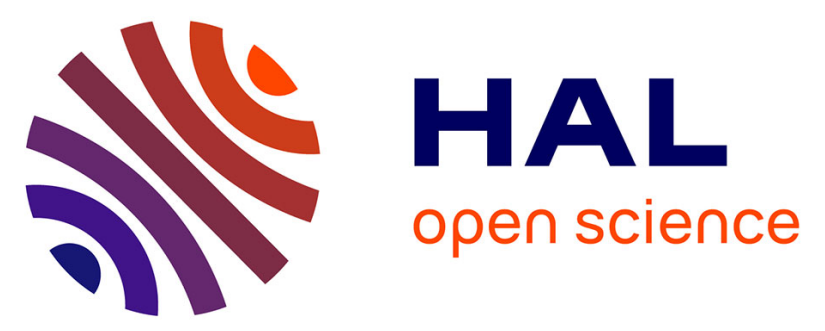

\title{
Tendon thickening in dialysis-related joint arthritis is due to amyloid deposits at the surface of the tendon
}

Johanna Sigaux, Imen Abdelkefi, Thomas Bardin, Jean-Denis Laredo, Hang-Korng Ea, Pablo Ureñatorres, Martine Cohen-Solal

\section{To cite this version:}

Johanna Sigaux, Imen Abdelkefi, Thomas Bardin, Jean-Denis Laredo, Hang-Korng Ea, et al.. Tendon thickening in dialysis-related joint arthritis is due to amyloid deposits at the surface of the tendon. Joint Bone Spine, 2019, 86, pp.233 - 238. 10.1016/j.jbspin.2018.08.005 . hal-03486427

\section{HAL Id: hal-03486427 \\ https://hal.science/hal-03486427}

Submitted on 20 Dec 2021

HAL is a multi-disciplinary open access archive for the deposit and dissemination of scientific research documents, whether they are published or not. The documents may come from teaching and research institutions in France or abroad, or from public or private research centers.
L'archive ouverte pluridisciplinaire HAL, est destinée au dépôt et à la diffusion de documents scientifiques de niveau recherche, publiés ou non, émanant des établissements d'enseignement et de recherche français ou étrangers, des laboratoires publics ou privés.

\section{(ㅇ)(1) $\$$}

Distributed under a Creative Commons Attribution - NonCommerciall 4.0 International 
Tendon thickening in dialysis-related joint arthritis is due to amyloid deposits at the surface of the tendon

\section{Johanna Sigaux ${ }^{1,2}$, Imen Abdelkefi ${ }^{1,2}$, Thomas Bardin ${ }^{1,2}$, Jean-Denis Laredo ${ }^{3}$, Hang-}

Korng Ea ${ }^{1,2}$, Pablo UreñaTorres ${ }^{4,5,6}$ and Martine Cohen-Solal ${ }^{1,2}$

${ }^{\mathbf{1}}$ Department of rheumatology, Hôpital Lariboisière

${ }^{2}$ university Paris 7, 75013 Paris, France

${ }^{3}$ Department of bone and joint imaging, Hôpital Lariboisière and university

${ }^{4}$ Ramsay-Générale de Santé, Clinique du Landy, 93400 Saint Ouen, France

${ }^{5}$ Department of Nephrology and Dialysis and Department of Renal Physiology, Necker Hospital, 75015 Paris, France

${ }^{6}$ University of Paris Descartes - 75006 Paris, France.

Corresponding author:

Martine Cohen-Solal

Department of rheumatology and INSERM U1132

Hôpital Lariboisière,

75010 Paris, France

Phone : +33149956358

E-mail: martine.cohen-solal@inserm.fr 


\section{Abstract}

Objectives: Beta-2 microglobulin $(\beta 2 \mathrm{M})$ dialysis-related amyloidosis (DRA), a disabiliting joint disease, has been initially reported in patients under long-term dialysis. The incidence and prevalence has significantly decreased with the improvement in dialysis techniques. Here, we attempted to clarify the clinical and MRI features to improve the diagnosis.

Methods: We retrospectively reviewed the files of 19 patients under dialysis treatment referred for suspicion of $\beta 2 \mathrm{M}$ DRA. The diagnosis was based on MRI criteria (low signal intensity on both T1- and T2-weighted MR sequences). MRI analysis included a scoring of the several joint lesions. Scores were quantified according to a severity scale (0 to 3$)$.

Results: Patients had a mean age of $66.0 \pm 10.5$ years and mean dialysis duration of $23.7 \pm$ 10.5 years. DRA affected mainly large joints (shoulder in $73.7 \%$, hip in $47.3 \%$ ) and spine (36.8\%). MRI images for 8 shoulders, 8 hips, and 3 spines were analysed. Amyloid synovitis was present in all cases, with high mean scores in the three sites. In all joints, the most common lesions were tendon thickening $(68.4 \%)$ and bone erosions $(68.4 \%)$. The mean tendon thickening score was high, particularly at the shoulders and also at the spine. Bone erosions were most frequent in the shoulder and pelvis.

Conclusion: In patients under long-term dialysis, $\beta 2 \mathrm{M}$ DRA involves large joints but also the spine. Special awareness should be drawn by the thickening of the tendon. MRI is required to characterize the pattern of the lesions and to achieve the diagnosis.

Keywords: $\beta 2$-microglobulin, dialysis, amyloidosis, arthropathy, magnetic resonance imaging 


\section{Introduction}

Dialysis-related amyloidosis (DRA) impairs the quality of life of patients under long-term dialysis because it is associated with significant morbidity and disability. Amyloidosis is defined by the deposition of the insoluble protein $\beta 2$ microglobulin $(\mathrm{B} 2 \mathrm{M})$ in the extracellular spaces of several tissues such as lungs, heart and gastrointestinal tract, with predominant deposition in joints $(1,2)$. In chronic kidney disease (CKD), joints are mainly affected and generate pain and swelling and result in erosive arthropathies (3). The lesions have been reported to be consistently associated with a carpal tunnel syndrome, which is related to the deposition of B2M amyloid fibrils at the wrist.

DRA occurs in patients under long-term hemodialysis and with markedly increased serum level of $\mathrm{B} 2 \mathrm{M}$ (4). Because of the lack of clearance by the kidney, the circulating $\mathrm{B} 2 \mathrm{M}$ is retained in the bloodstream, which then favours the deposition of the folding and fibrillary protein in articular and bone tissues, as histologically confirmed by joint biopsies (5). This dialysis-related outcome was initially reported in the 1980s in relation to the use of low-flux cellulosic dialysis membranes, namely cuprophane, which failed to filter high-and mediummolecular-weight proteins. Consistently, the duration of dialysis appeared to be a predominant risk factor, because amyloidosis occurred in patients with dialysis duration above 15 years (6). The prevalence has substantially decreased with the development of new dialysis strategies that enhance the clearance of $\mathrm{B} 2 \mathrm{M}$, such as the use of efficient high-flux membranes, hemofiltration, and immune-adsorption, as well as the development of kidney transplantation (7-9).

Nevertheless, DRA remains a recurrent cause of morbidity, the diagnosis of which is underestimated because of poor clinical and imaging awareness. Here we report the 
experience with DRA in a bone and joint reference centre for patients with CKD. We aimed to characterize DRA in terms of clinical and MRI criteria and to focus on the main criterion to achieve the diagnosis and reduce underestimation of the disease.

\section{Methods}

\subsection{Patients}

We retrospectively analysed the medical records for 19 patients under dialysis therapy who had been referred for arthritis in the centre from 2000 to 2016. All patients reported subacute pain accompanied by swelling that affected one or more joints. Patients did not have any fever, but all displayed warm and red joints suggesting local inflammation. Synovial fluids eliminated septic origin. We collected data on clinical characteristics (age, gender, cause of nephropathy, duration of dialysis) and number of swollen joints. The study was approved by the ethical committee of the Assistance Publique-Hopitaux de Paris that allows the use of the data obtained for usual care.

\subsection{Characterisation of DRA lesions by MRI}

All patients underwent standard radiography and MRI of the symptomatic joints, which confirmed the diagnosis. An MRI of each symptomatic joint was obtained with conventional spin-echo T1- and T2-weighted images in the axial and coronal planes. Images were analysed blindly by a musculoskeletal radiologist (JDL) and a rheumatologist (TB). No gadoliniumenhanced MR sequences were obtained given the altered renal function. The following criteria were used to classify and score each lesion (Table I) and a mean score was calculated for the shoulder, hip and spine. 
-Thickening of the synovium, muscle or bursa including low signal intensity on both T1- and T2-weighted images consistent with amyloid deposits (score 0 to 2 according to the volume)

- Thickening of the synovium, muscle or bursa with low signal intensity on T1-weighted images and high signal intensity on T2-weighted images were considered inflammatory synovitis and bursitis (score 0 to 2 according to the volume)

- Presence of bone marrow oedema (score 0 to 2 according to the extent)

- Number of bone erosions (score 0 to 3; 3 defined by 3 erosions or more)

-Bone cysts (score 0 to 2 according to the volume)

\subsection{Statistical analysis}

Data were expressed as percentages, mean \pm standard deviation or standard error of the mean and range as appropriate.

The association between amyloid synovitis and other MRI parameters including bone erosions, amyloid bursitis, muscle amyloidosis, tendon thickening, bone cysts, bone marrow edema and bursa thickening was analyzed by Fisher's exact test. Statistical analyses were performed using XLSTAT 2017: Data Analysis and Statistical Solution for Microsoft Excel. Addinsoft, Paris, France (2017). Results were considered statistically significant when $\mathrm{p}<0.05$.

\subsection{Role of the funding source}

There is no funding source.

\section{Results}

\section{$\underline{3.1}$ Characteristics of patients}

The 19 patients under dialysis ( 12 men and 7 women; mean age $66.0 \pm 10.5$ years, range $6-$ 41; mean dialysis duration $23.7 \pm 10.5$ years) were affected by joint amyloidosis (Table II); 13 
patients were receiving oral corticosteroid therapy at a mean dose of $5.7 \mathrm{mg} /$ day because of chronic joint effusion, and 7 patients had a history of one or more synoviortheses of the large joints as a treatment for chronic effusion.

Twelve patients $(63.1 \%)$ had a history of surgery for carpal tunnel syndrome (2 unilateral, 10 bilateral). For all patients, the diagnosis was based on clinical features of joint swelling, no fever, and the absence of crystals in joint fluid and negative immunological tests.

Amyloid tissues involved mainly the large joints such as the shoulders $(14 / 19,73.7 \%)$, hips $(9 / 19,47.3 \%)$, knees $(7 / 19,36.8 \%)$ and also smaller joints such as the cervical and lumbar spine $(7 / 19,36.8 \%)$. Patients had a mean of 2affected joints, and duration on dialysis was longer for those with more than 2 joints affected than only 1or 2 joints affected (30.8 vs17.3 years of dialysis).

\subsection{Characteristics and frequency of MRI parameters}

We analysed 19 MR images of joints ( 8 shoulders, 8 hips, and 3 spines). All patients showed amyloid synovitis, which was a consistent finding in all shoulders and hips (Table I, Figure 1). All the MRI parameters were observed at a frequency above $50 \%$ except for inflammatory synovitis or bursitis and bone marrow oedema (table 1). However, they revealed that concomitant lesions of inflammation of the synovium or bursa as shown any decreased T1and increased T2-weighted signals $(6 / 19,31.6 \%)$.

Seven of 8 shoulders showed an apparent thickening at the humeral insertion of the supraspinatus tendon. Both T1- and T2-weighted images showed thickening of the tendon, as revealed by low signal intensity, which was observed in 13 out of the 19 joints $(68.4 \%)$. A closer examination showed that this was due to the deposition of soft tissues in both deep and superficial parts of the tendon, whereas the tendon itself had a normal or sometimes decreased thickness, leading sometimes to complete or partial tear $(3 / 8,37.5 \%$ of shoulders). Such an 
apparent "pseudo-thickening" was found in the gluteus medius tendon in 3/8 (37.5\%) of hips and the ligamentum flavum as well as the spinal supra-spinous ligament in all spines. In addition, we found a high number of erosions in different joints. Erosions were particularly frequent at the hip, mainly located at the femoral neck, greater trochanter and acetabulum. At the shoulder, erosions were usually marginal at the site of tendon insertion of the synovial tissue. Bone erosions were also seen in multiple consecutive vertebral end-plates on lumbar and cervical-spine MRI (Figure 1). However, cysts were fewer than erosions $(<50 \%)$.

\subsection{Association of MRI lesions}

Table 2 summarizes the MRI parameters in each joint. Amyloid synovitis was present in all joints. We found a high prevalence of bone erosions $(13 / 19,68.4 \%)$ and tendon thickening (13/19, 68.4\%). Table 2 and Figure 2 show the distribution of the lesions in the joint sites. Amyloid synovitis had the highest scores at the shoulder, hip and spine. Bone erosions were most frequent at the shoulders, hips and less frequent at the spine. Of note, tendon thickening was highly present and with high scores at the shoulders $(1.75 \pm 0.7)$ and at the spine $(1.66 \pm 0.57)$, but rarer at the pelvis $(0.62 \pm 0.91)$. Amyloid bursitis had a high score at the shoulder $(1.25 \pm 1.03)$ versus the pelvis $(0.62 \pm 0.74)$. Bone-marrow oedema was rare at any site $(0.12 \pm 0.35$ for the shoulder, $0.12 \pm 0.35$ for the hip and $0.33 \pm 0.57$ for the spine).

Figure 3 illustrates the frequency of the association of the various parameters with amyloid synovitis. No parameter, including bone erosions, amyloid bursitis, muscle amyloidosis and tendon thickening, was associated with amyloid synovitis (all p >0.05).

\section{Discussion}


We describe the clinical and MRI features of B2M amyloidosis arthropathy in patients undergoing long-term dialysis therapy. Although currently rare, joint involvement remains despite the improvement in dialysis technology $(10,11)$ and could be underestimated. Here, we show that joint pain and effusions affected mainly large joints, although carpal tunnel syndrome was not constant, as previously reported $(12,13)$. As well, duration of dialysis therapy was a determining factor of the prevalence and severity of joint disorders. Such disorders occur after long-term dialysis such as 30 years or more (10), but could be also observed after shorter duration such as after 6 years as in our series.

At best, the diagnosis of dialysis-related B2M amyloidosis usually requires histological confirmation. However, MRI contributes to the detection of several associated lesions in articular and periarticular soft tissues, thereby being a useful tool when biopsy is not possible, as previously reported $(14,15)$. The low signal intensity in both T1- and T2weighted MRI images is likely due to the poor cellularity and the fibrous nature of amyloidcontaining tissues (16). Besides, inflammatory lesions defined by low T1 and high T2 signals can be associated with amyloid lesions, and might overlook the amyloidosis deposits. A particularly striking observation was the presence of tendon thickening in all spines, including the ligamentum flavum and supra-spinous ligament. Of note, we here report a high prevalence of $68 \%$ of amyloidosis affecting the spinal tendon. Besides scarce descriptions of increased thickness of the supraspinatus tendon $(15,17)$, other structures could be involved and therefore should be investigated in the presence of lumbar pain. As suggested by the signal intensity, the tendon thickening is related to the deposition of amyloid tissue on the deep and superficial aspects of the tendon while the tendon itself has a normal or even decreased thickness. We also found a thickening of the tendons in the shoulder and hip leading sometimes to complete or partial tear, which might lead to the compression of the component of the acromio-humeral 
space (18). Thickening of the ilio-femoral portion of the joint capsule of the hip was also seen on MRI in symptomatic and asymptomatic patients (15).

Bone erosions were frequently observed, but they had no significant association with amyloid synovitis. Bone erosions, mainly present at the large joints, are at the insertion of the synovial tissue, capsule and ligaments. The general mechanisms of amyloid tissue formations are still not clearly understood. A suggestion was that partial unfolding B2M proteins were prerequisite to nucleus formation and then the extension of amyloid fibrils at neutral $\mathrm{pH}$ $(19,20)$. The fibril formation is then catalysed by many biological molecules in the synovial tissue (21). The depolymerisation of the fibrils is reduced by the presence of glycosaminoglycans, proteoglycans or lipids such apoE (19). Many investigators reported that B2M amyloid fibrils are cytotoxic to many cell types and might induce cell death (20). Porter et al. showed a direct cytotoxicity of B2M in monocytes, which promotes the formation of osteoclasts and activates bone resorption (22). The frequency of bone erosions illustrates the activation of osteoclastic bone resorption, which was not compensated by an osteoblastic bone formation, thereby resulting in a negative bone balance and local bone loss (23). Several possible mechanisms of bone resorption were described in relation to the inflammatory environment (24). Synovial infiltrating cells around amyloid deposits such as CD4+ T cells express RANKL, which stimulates osteoclast differentiation or other inflammatory cytokines such as tumor necrosis factor $\alpha$ and interleukin $1 \beta$ are released around amyloid deposits by inflammatory cells $(24,25)$. Local increased concentration of fibroblast growth factor 23 has also been shown to stimulate bone resorption (26). Here, erosions were localized at the shoulder or hip, large joints with synovium in close contact with bone, and in rare cases, might promote spontaneous fractures (27). Indeed, bone erosions occurred also at the spine, localized at the lower segment of the cervical spine, as described previously (28). They might 
be less common there than in large joints because of the small amount of synovial tissue in the intervertebral spaces. However, amyloid synovitis is not correlated with the other parameters, although previously described $(15,29)$, indicating several profiles among the patients in whom some features are more developed than others.

In conclusion, we provide evidence that MRI allows a clear identification of dialysis-related B2M amyloidosis in patients under long-term dialysis therapy, which suggests that MRI could be a useful tool for early diagnosis and should be done in a systematic basis. Amyloid synovitis is the most common lesion, but thickening of the tendon and bone erosions give supplementary arguments favouring the diagnosis. Early diagnosis of this affection might modify the modality of dialysis therapy and result in the lowest morbidity.

Conflict of interest statement: none declared

\section{Authors' contributions:}

Johanna Sigaux: Conception, analysis and interpretation of data, drafting the article Imen Abdelkefi: analysis and interpretation of data, drafting the article

Thomas Bardin: reading the MRI, providing intellectual content of critical importance, revising the article

Jean-Denis Laredo: reading the MRI, providing intellectual content of critical importance, revising the article

Hang-Korng Ea: revising the article

Pablo Ureña Torres: providing intellectual content of critical importance, drafting the article Martine Cohen-Solal: Conception, analysis and interpretation of data, drafting the article or revising it. 
All gave the final approval of the version to be published.

\section{References}

1. Ogoshi T, Kawanami T, Yatera K, Mukae H. Dialysis-related Amyloidosis with Diffuse Parenchymal Lung Involvement. Intern Med. 2012;51(23):3303-4.

2. Saito A, Gejyo F. Current Clinical Aspects of Dialysis-Related Amyloidosis in Chronic Dialysis Patients. Ther Apher Dial. 2006;10(4):316-20.

3. Kurer MH, Baillod RA, Madgwick JC. Musculoskeletal manifestations of amyloidosis. A review of 83 patients on haemodialysis for at least 10 years. J Bone Joint Surg Br. $1991 ; 73(2): 271-6$.

4. Jadoul M, Drüeke TB. $\beta_{2}$ microglobulin amyloidosis: an update 30 years later. Nephrol Dial Transplant. 2016;31(4):507-9.

5. Jadoul M, Garbar C, Noël H, et al. Histological prevalence of beta 2-microglobulin amyloidosis in hemodialysis: a prospective post-mortem study. Kidney Int. $1997 ; 51: 1928-32$

6. van Ypersele de Strihou C. [Morphogenesis of beta $2 \mathrm{~m}$ (A beta $2 \mathrm{~m}$ ) amyloid deposits in dialysis patients]. Bull Mem Acad R Med Belg. 2000;155:273-8.

7. Schiffl H. Impact of advanced dialysis technology on the prevalence of dialysis-related amyloidosis in long-term maintenance dialysis patients. Hemodial Int. 2014;18(1):13641.

8. Schwalbe S, Holzhauer M, Schaeffer J, Galanski M, Koch KM, Floege J. Beta 2microglobulin associated amyloidosis: a vanishing complication of long-term hemodialysis? Kidney Int. 1997;52(4):1077-83.

9. Hoshino J, Yamagata K, Nishi S, et al. Significance of the decreased risk of dialysisrelated amyloidosis now proven by results from Japanese nationwide surveys in 1998 
and 2010. Nephrol Dial Transplant. $2016+; 31(4): 595-602$.

10. Yamamoto S, Kazama JJ, Maruyama H, Narita I. Dialysis-Related Amyloidosis : Pathogenesis and Clinical Features in Patients Undergoing Dialysis Treatment. Japan: INTECH;2013. p. 67-83.

11. Yamamoto S, Kazama JJ, Maruyama H, Nishi S, Narita I, Gejyo F. Patients undergoing dialysis therapy for 30 years or more survive with serious osteoarticular disorders. Clin Nephrol. 2008;70(6):496-502.

12. Danesh F, Ho LT. Dialysis-related amyloidosis: history and clinical manifestations. Semin Dial. 2001;14(2):80-5.

13. Nishi S, Hoshino J, Yamamoto S, et al. A multicenter cross sectional study for bonearticular lesions associated with dialysis related amyloidosis in Japan. Nephrology (Carlton). 2018;23:640-5.

14. Otake S, Tsuruta Y, Yamana D, Mizutani H, Ohba S. Amyloid arthropathy of the hip joint: MR demonstration of presumed amyloid lesions in 152 patients with long-term hemodialysis. Eur Radiol. 1998;8(8):1352-6.

15. Escobedo EM, Hunter JC, Zink-Brody GC, Andress DL. Magnetic resonance imaging of dialysis-related amyloidosis of the shoulder and hip. Skeletal Radiol. 1996;25(1):418.

16. Karakida O, Aoki J, Kanno Y, et al. Hemodialysis-related arthropathy. A prospective MR study with SE and GRE sequences. Acta Radiol. 1997;38(1):158-64.

17. Dervisoglu E, Anik Y, Erdogan S, Akansel G, Yilmaz A. $\beta_{2}$-Microglobulin Amyloidosis in Hemodialysis and Peritoneal Dialysis Patients. Ther Apher Dial. 2008;12(4):306-10.

18. Bernageau J, Bardin T, Goutallier D, Voisin MC, Bard M. Magnetic resonance imaging findings in shoulders of hemodialyzed patients. Clin Orthop Relat Res. 1994 ;304:91- 
6.

19. Eichner T, Radford SE. Understanding the complex mechanisms of $\beta 2$-microglobulin amyloid assembly. FEBS J. 2011;278(20):3868-83.

20. Naiki H, Okoshi T, Ozawa D, Yamaguchi I, Hasegawa K. Molecular pathogenesis of human amyloidosis: Lessons from $\beta_{2}$-microglobulin-related amyloidosis. Pathol Int. 2016;66(4):193-201.

21. Kumar S, Sharma P, Arora K, Raje M, Guptasarma P. Calcium Binding to Beta-2Microglobulin at Physiological Ph Drives the Occurrence of Conformational Changes Which Cause the Protein to Precipitate into Amorphous Forms That Subsequently Transform into Amyloid Aggregates. PLoS One 9:e95725 .

22. Porter MY, Routledge KE, Radford SE, Hewitt EW. Characterization of the Response of Primary Cells Relevant to Dialysis-Related Amyloidosis to $\beta 2$-Microglobulin Monomer and Fibrils. PLoS One. 2011;6(11):e27353.

23. Menaa C, Esser E, Sprague SM. $\beta 2$-Microglobulin stimulates osteoclast formation. Kidney Int. 2008;73(11):1275-81.

24. Kazama JJ, Maruyama H, Gejyo F. Osteoclastogenesis and osteoclast activation in dialysis-related amyloid osteopathy. Am J Kidney Dis. 2001;38(4) Suppl 1:S156-60.

25. Iida Y, Miyata T, Inagi R, Sugiyama S, Maeda K. Beta 2-microglobulin modified with advanced glycation end products induces interleukin-6 from human macrophages: role in the pathogenesis of hemodialysis-associated amyloidosis. Biochem Biophys Res Commun. 1994;201(3):1235-41.

26. David V, Francis C, Babitt JL. Ironing out the cross talk between FGF23 and inflammation. Am J Physiol - Ren Physiol. 2017;312(1):F1-8.

27. Bataille S, Fernandez C, Zink J-V, Brunet P, Berland Y, Burtey S. The Case / A hip fracture in a hemodialysis patient. Pathologic right-hip fracture from $\beta 2$-microglobulin 
amyloidosis. Kidney Int. 2013;83(6):1211-2.

28. Theodorou DJ, Theodorou SJ, Resnick D. Imaging in the Dialysis Patient: Imaging in Dialysis Spondyloarthropathy. Semin Dial. 2002;15(4):290-6.

29. Cobby MJ, Adler RS, Swartz R, Martel W. Dialysis-related amyloid arthropathy: MR findings in four patients. AJR Am J Roentgenol. 1991;157(5):1023-7. 


\section{Figure legend}

Figure1: Amyloid lesions on T1 and T2-weighted MR images

A: lesions of an 84-year-old man with a 17-year history of hemodialysis. 1 T1-weighted coronal MR image of shoulder shows decreased signal intensity in multiple nodular lesions in humeral head (white arrow) and bicipital groove (black arrow). Thickening of supraspinatus tendon leading to tendinous rupture was also noted (empty arrow). 2: T2-weighted MR image of shoulder showing the same lesions with low signal intensity with a fluid collection in the biceps tendon sheath.

B: lesions of 61-year-old women with a 34-year history of hemodialysis. 1 T1-weighted sagittal MR image of spine showing decreased signal intensity of L4 and L5 vertebral endplates. Anterolisthesis of L4 on L5 associated with abnormal tissue anterior and posterior to the dural sac impinging on spinal cord was seen (white arrow). 2 T2-weighted sagittal MR image of spine showing abnormal areas of decreased signal intensity seen in 1 also showed decreased signal intensity on T2-weighted images.

C: lesions of a 45-year-old man with a 30-year history of hemodialysis. 1 T1-weighted axial MR image of hips showing decreased signal intensity of nodular lesions in femoral head (white arrow) associated with synovial thickening mainly on the left hip (black arrow). 2 T2weighted image of hips showing decreased signal intensity in the marginal nodular lesion and synovial tissue.

Figure 2: Mean score of MRI characteristics of each joint site.

Scoring of lesions was based on the degree of amyloid deposits. For bone erosions, it ranged from 0 to 3 according to number of erosions 0,1 , or 2 ; or 3 if $>3$. For the other features (amyloid synovitis, inflammatory synovitis, tendon thickening, bursa thickening, amyloid 
bursitis, inflammatory bursitis, cysts, muscle amyloidosis and bone marrow edema), the score ranged from 0 to 2 by volume of amyloid infiltration.

\section{Figure 3: Association between amyloid synovitis and other MRI parameters.}

Bone erosions, amyloid bursitis and tendon thickening were frequent in the absence (grey bars) or presence of amyloid synovitis (black bars). However, no parameter was significantly associated with amyloid synovitis. 
Table 1: Mean score and frequency of MRI parameters for joint sites

\begin{tabular}{|c|c|c|c|c|c|c|c|}
\hline \multirow[t]{2}{*}{ Features } & \multicolumn{2}{|c|}{$\begin{array}{l}\text { Shoulder } \\
\qquad(\mathrm{N}=8)\end{array}$} & \multicolumn{2}{|c|}{$\begin{array}{l}\text { Pelvis } \\
(\mathrm{N}=8)\end{array}$} & \multicolumn{2}{|c|}{$\begin{array}{l}\text { Spine } \\
(\mathrm{N}=3)\end{array}$} & \multirow{2}{*}{$\begin{array}{c}\text { All joints } \\
\\
\text { Frequency } \\
(\%)\end{array}$} \\
\hline & $\begin{array}{c}\text { Mean } \pm \\
\text { SEM }\end{array}$ & Range & $\begin{array}{c}\text { Mean } \pm \\
\text { SEM }\end{array}$ & Range & $\begin{array}{c}\text { Mean } \pm \\
\text { SEM }\end{array}$ & Range & \\
\hline Amyloid synovitis (0-2) & $1.87 \pm 0.35$ & $(1-2)$ & $1.75 \pm 0.46$ & $(1-2)$ & $1.66 \pm 0.57$ & $(1-2)$ & 100 \\
\hline Bone erosions $(0-3)$ & $1.62 \pm 1.5$ & $(0-3)$ & $1.87 \pm 1.35$ & $(0-3)$ & $1 \pm 1$ & $(0-2)$ & 68.4 \\
\hline Amyloid bursitis (0-2) & $1.25 \pm 1.03$ & $(0-2)$ & $0.62 \pm 0.74$ & $(0-2)$ & - & - & 56.2 \\
\hline Muscle amyloidosis (0-2) & $0.87 \pm 0.99$ & $(0-2)$ & $0.62 \pm 0.74$ & $(0-2)$ & - & - & 50 \\
\hline Tendon thickening (0-2) & $1.75 \pm 0.7$ & $(0-2)$ & $0.62 \pm 0.97$ & $(0-2)$ & $1.66 \pm 0.57$ & $(1-2)$ & 68.4 \\
\hline Bursa thickening $(0-2)$ & $0.5 \pm 0.75$ & $(0-2)$ & $0.25 \pm 0.46$ & $(0-1)$ & - & - & 31.2 \\
\hline Inflammatory synovitis $(0-2)$ & $0.5 \pm 0.54$ & $(0-1)$ & 0 & 0 & 0 & 0 & 15.7 \\
\hline Cysts $(0-2)$ & $0.62 \pm 0.74$ & $(0-2)$ & $0.62 \pm 0.91$ & $(0-2)$ & 0 & 0 & 36.8 \\
\hline Inflammatory bursitis $(0-2)$ & $0.25 \pm 0.46$ & $(0-1)$ & $0.12 \pm 0.35$ & $(0-1)$ & - & - & 18.7 \\
\hline Bone-marrow oedema $(0-2)$ & $0.12 \pm 0.35$ & $(0-1)$ & $0.12 \pm 0.35$ & $(0-1)$ & $0.33 \pm 0.57$ & $(0-1)$ & 15.8 \\
\hline
\end{tabular}

The images of 19 joints were obtained and scored as described in the method section. Scoring of each lesion was based on the degree of amyloid deposits. For bone erosions, it ranged from 0 to 3 according to number of erosions 0,1 , or 2 ; or 3 if $>3$ erosions. For the remaining features (amyloid synovitis, inflammatory synovitis, tendon thickening, bursa thickening, amyloid bursitis, inflammatory bursitis, cysts, muscle amyloidosis and bone marrow oedema), it ranged from 0 to 2 by volume of amyloid infiltration. Results are shown as means and SEM. 
Table 2: Patient characteristics

\begin{tabular}{|c|c|c|c|c|c|c|}
\hline $\mathbf{N}^{\circ}$ & Sex & $\begin{array}{l}\text { Age } \\
\text { (yrs) }\end{array}$ & $\begin{array}{c}\text { Duration } \\
\text { dialysis (yrs) }\end{array}$ & Type of Kidney disease & Sites & $\begin{array}{l}\text { Carpal } \\
\text { tunnel }\end{array}$ \\
\hline 1 & $M$ & 78 & 11 & Alport syndrome & $\mathrm{H}$ & unilateral \\
\hline 2 & $\mathrm{~F}$ & 75 & 7 & Hypertensive nephropathy & $\mathrm{K}$ & 0 \\
\hline 3 & $\mathrm{M}$ & 53 & 34 & Reflux nephropathy & $\mathrm{K}, \mathrm{S}, \mathrm{Sp}$ & bilateral \\
\hline 4 & $M$ & 52 & 9 & Undetermined & $\mathrm{S}$ & 0 \\
\hline 5 & $\mathrm{~F}$ & 67 & 20 & Polycystic kidney disease & $\mathrm{H}$ & 0 \\
\hline 6 & $M$ & 61 & 29 & $\begin{array}{l}\text { Familial hemolytic and uremic } \\
\text { syndrome }\end{array}$ & $\mathrm{K}, \mathrm{S}, \mathrm{Sp}$ & bilateral \\
\hline 7 & $\mathrm{~F}$ & 61 & 29 & $\begin{array}{l}\text { Membranoproliferative } \\
\text { glomerulonephritis }\end{array}$ & K, S, Sp & bilateral \\
\hline 8 & $\mathrm{M}$ & 84 & 17 & Chronic pyelonephritis & $\mathrm{S}$ & 0 \\
\hline 9 & $\mathrm{M}$ & 73 & 37 & Familial glomerulonephritis & $\mathrm{K}, \mathrm{H}, \mathrm{S}$ & unilateral \\
\hline 10 & $\mathrm{M}$ & 68 & 31 & Chronic interstitial nephritis & $\mathrm{S}, \mathrm{Sp}$ & bilateral \\
\hline 11 & $\mathrm{~F}$ & 61 & 34 & Lipoidic nephrosis & $\mathrm{H}, \mathrm{S}, \mathrm{Sp}$ & bilateral \\
\hline 12 & $M$ & 67 & 34 & $\begin{array}{l}\text { Focal segmental } \\
\text { glomerularsclerosis }\end{array}$ & $\mathrm{H}, \mathrm{S}, \mathrm{Sp}$ & bilateral \\
\hline 13 & $\mathrm{M}$ & 45 & 30 & Reflux nephropathy & $H, S, W$ & bilateral \\
\hline 14 & $\mathrm{~F}$ & 70 & 41 & Undetermined & $\begin{array}{c}\mathrm{K}, \mathrm{H}, \mathrm{S}, \\
\mathrm{W}\end{array}$ & bilateral \\
\hline 15 & $\mathrm{~F}$ & 80 & 10 & Undetermined & $\mathrm{H}, \mathrm{S}, \mathrm{Sp}$ & bilateral \\
\hline 16 & $\mathrm{M}$ & 70 & 36 & Hypertensive nephropathy & $\mathrm{S}$ & bilateral \\
\hline 17 & $M$ & 59 & 6 & HIV-associated nephropathy & $\mathrm{H}$ & 0 \\
\hline 18 & $\mathrm{M}$ & 54 & 30 & Nephronophtisis & K & 0 \\
\hline 19 & $\mathrm{~F}$ & 76 & 6 & Diabetic nephropathy & $S$ & 0 \\
\hline
\end{tabular}

Demographic characteristics were collected in 19 patients: Yrs: years, M: male, F: female, S: shoulder, H: hip, $\mathrm{K}$ : knee,Sp: spine, W: wrist, 
Figure 1
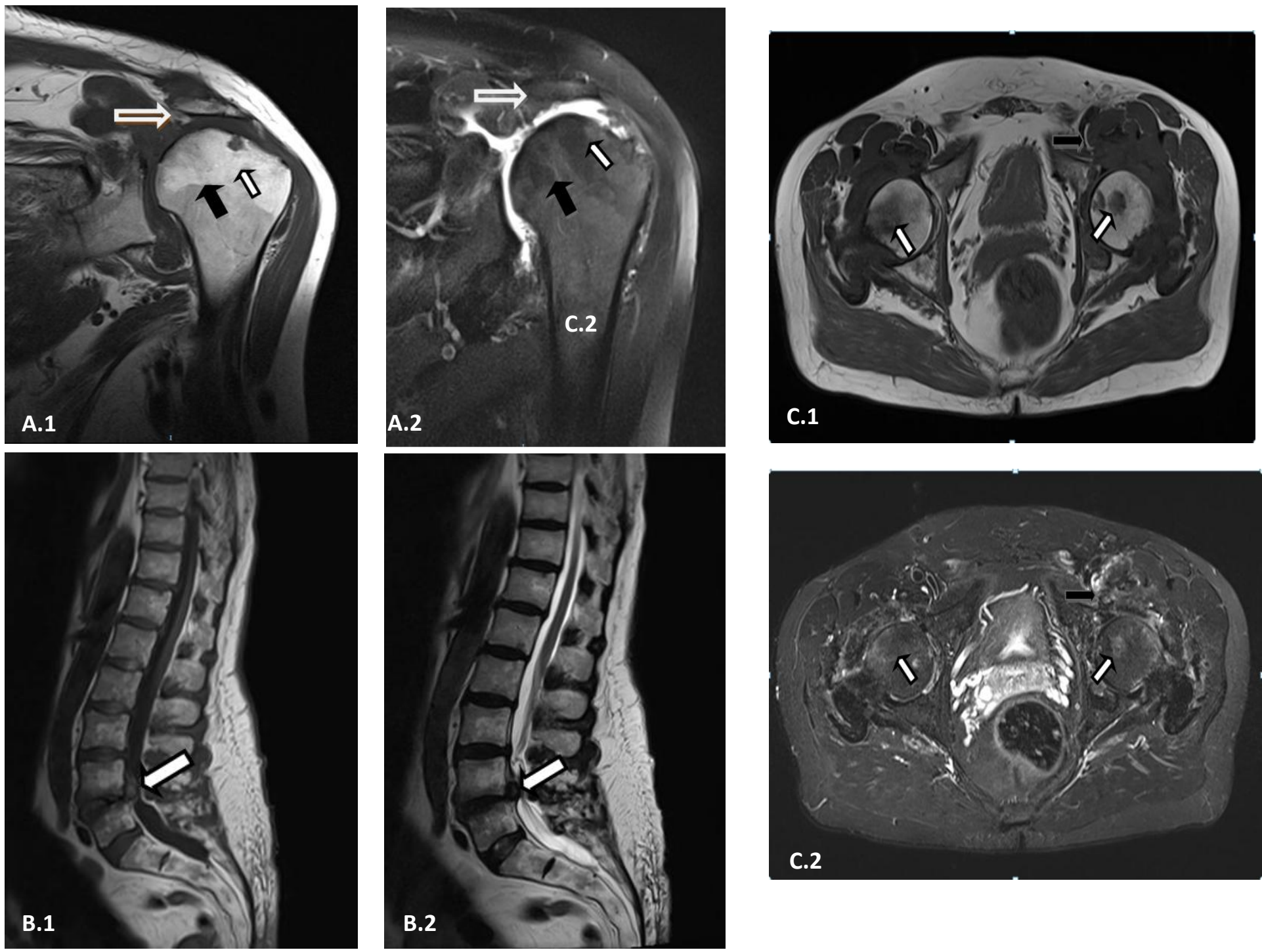


\section{Figure 2}

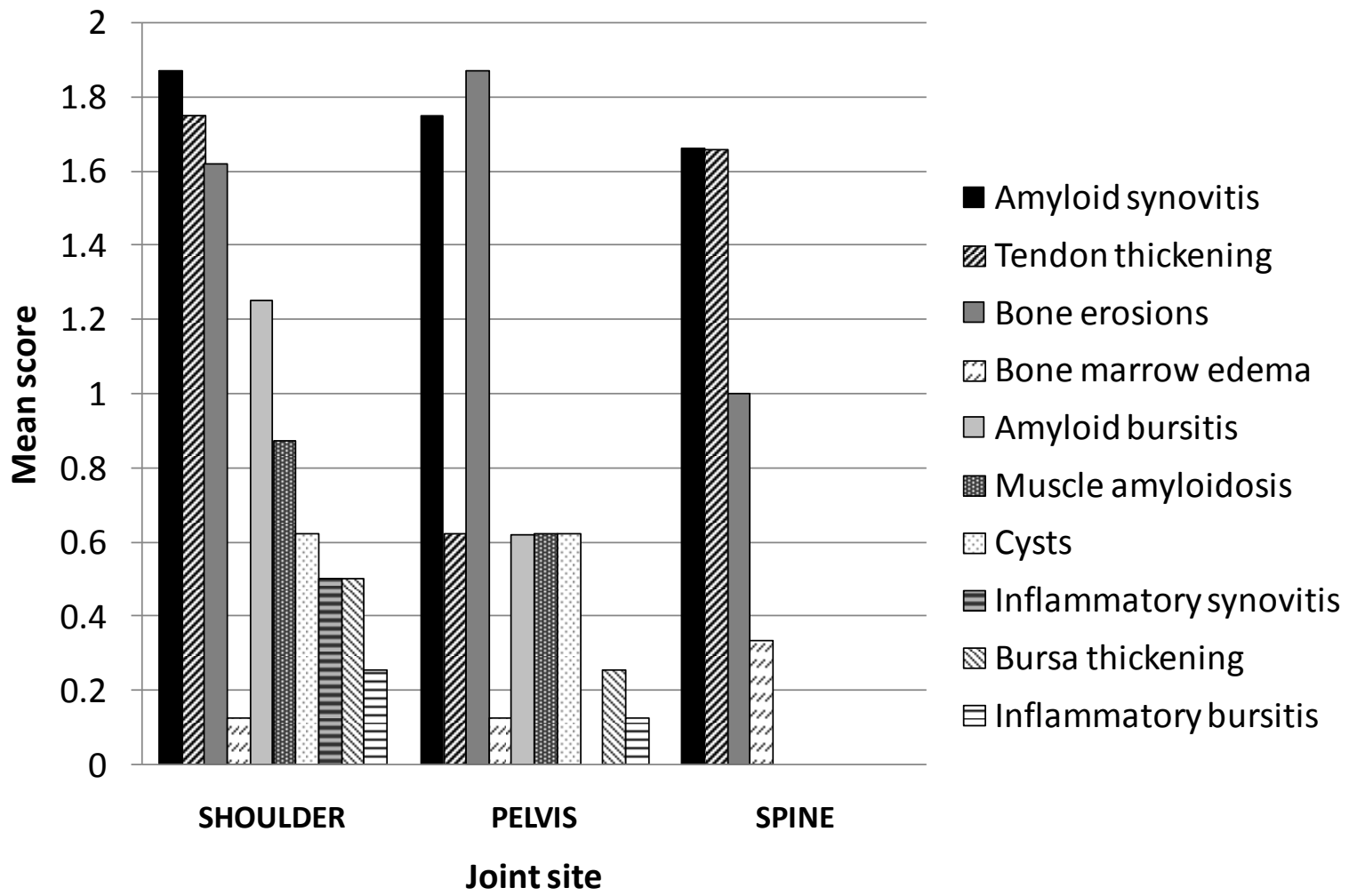




\section{Figure 3}

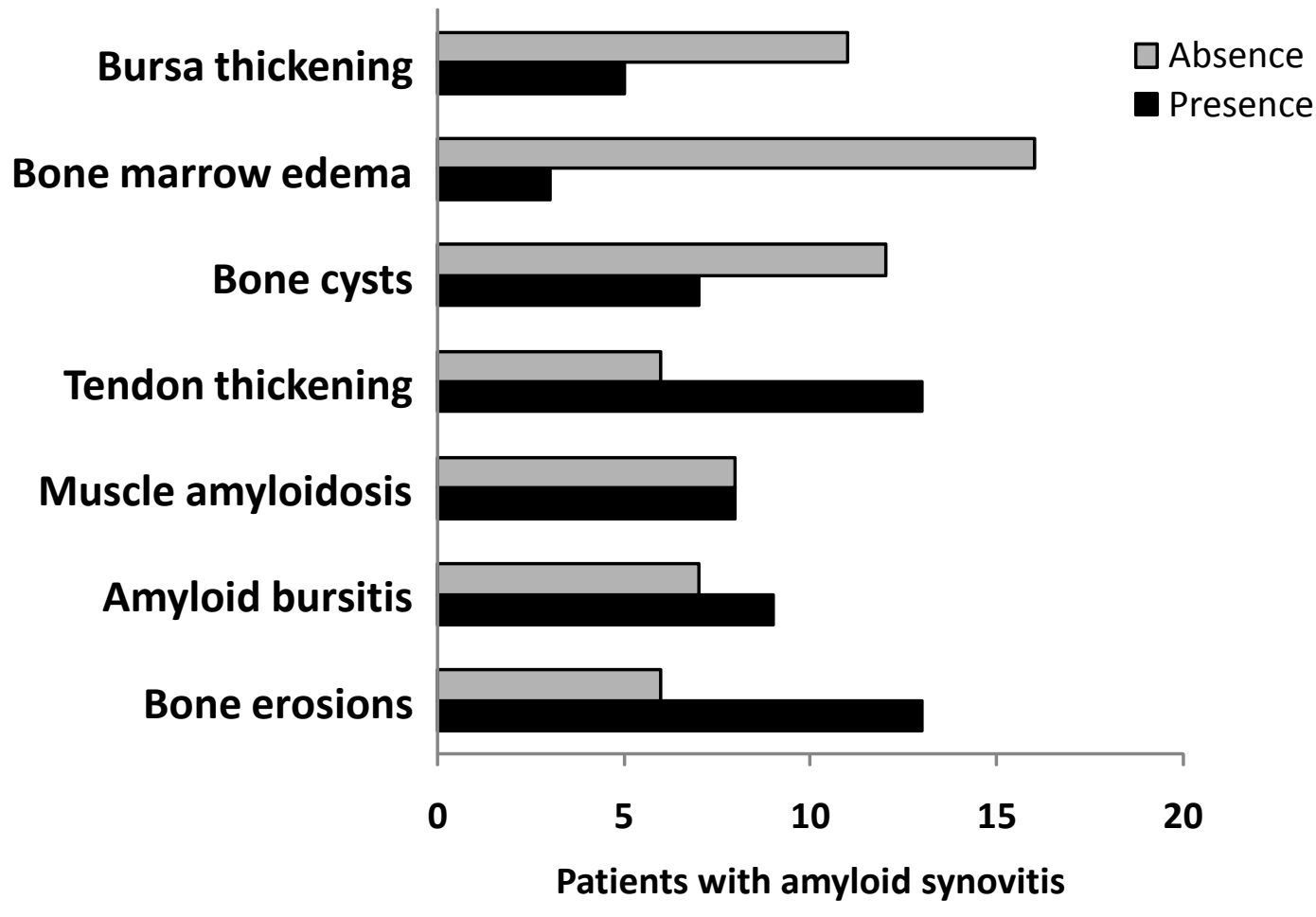

